\title{
Experimental Investigations on Dopamine Transmission Can Provide Clues on the Mechanism of the Therapeutic Effect of Amphetamine and Methylphenidate in ADHD
}

\author{
Ezio Carboni and Alessandra Silvagni \\ Department of Toxicology and "Centro di Eccellenza sulla Neurobiologia delle Dipendenze \\ University of Cagliari”, Via Ospedale 72, 09124 Cagliari, Italy
}

CONTENTS

Introduction

Animal Models of ADHD

Transmitters and Brain Areas Involved in ADHD

Mechanism of Action of Drugs Used in ADHD

Therapy

Synaptosomes Studies

Slices Studies

Whole Cell Studies

In vivo Studies

Discussion

References

\section{SUMMARY}

The aim of this review is to compare the experimental evidence obtained from in vitro studies on the effect of amphetamine and methylphenidate on dopamine transmission with the results obtained in animal models of attention deficit hyperactivity disorder (ADHD). This comparison can extend the knowledge on the mechanism of action of the drugs used in the therapy of ADHD and provide insight into

Reprint requests to: Ezio Carboni, e-mail: ecarboni@unica.it the etiology of ADHD. In particular, we considered the results obtained from in vitro methods, such as synaptosomes, cells in culture, and slices and from in vivo animal models of ADHD, such as spontaneous hypertensive rats (SHR) and the Naples high-excitability (NHE) rat lines. The different experimental approaches produce consonant results and suggest that in SHR rats, in contrast to Wistar Kyoto rats (WKY), amphetamine and depolarization by high $\mathrm{K}^{+}$might release different pools of dopamine-containing vesicles. The pool depleted by amphetamine might represent dopamine that is stored in large dense core vesicles, whereas dopamine released by high $\mathrm{K}^{+}$might be contained in small synaptic vesicles (SSV). The sustained dopamine transmission observed in the nucleus accumbens of SHR but not WKY rats can be supported by an elevated synthesis and release, which also might explain the stronger effect of methylphenidate on dopamine release in SHR but not in WKY rats. This hypothesis might enlighten the common therapeutic effect of these drugs, although their action takes place at different levels in catecholaminergic transmission.

\section{KEYWORDS}

dopamine, noradrenaline, nucleus accumbens, prefrontal cortex, SHR, VMAT2 


\section{INTRODUCTION}

Attention-deficit hyperactivity disorder (ADHD) is a clinically heterogeneous disorder with an onset in infancy characterized by the presence of three principal symptoms: hyperactivity, inattention, and impulsivity (Oades, 1998). Results from neuropsychological and neuroimaging studies suggest that abnormalities of the prefrontal cortex coexist with a dysfunction of subcortical areas that project to the prefrontal cortex, leading to the definition of 'frontosubcortical alteration', an expression that reflects the complexity of this disorder and answers questions on the site of the defect that causes ADHD (see Faraone \& Biederman, 2002, for review). The treatment of ADHD is represented by drugs that raise the synaptic concentration of dopamine and norepinephrine through different mechanisms. Although the first line of treatment is represented by psychostimulants like methylphenidate and dextroamphetamine (Whalen et al., 1989; Solanto, 1998), tricyclic antidepressants can be used while weighing the risks and benefits because of their moderate to strong side effects. Antidepressants that can be used in ADHD therapy are drugs like imipramine, desipramine, clomipramine, nortriptiline, and amytriptiline that block the reuptake of norepinephrine and serotonin (Wilens et al., 1995; Spencer et al., 2002; Pliszka, 2003), but not the selective serotonin reuptake inhibitor (SSRI) (Biederman et al., 1997).

The increase of catecholamine transmission, either at the level of the basal ganglia or at the level of the prefrontal cortex, might be the key to the medication potential of psychostimulants and antidepressants. The study of synaptosomes, slices, vesicles, and cells in culture has contributed to elucidating the mechanism of action of amphetamine and its involvement in vesicle trafficking at the catecholaminergic terminal level. This issue was recently reviewed by Schmitz et al. (2003). The aim of the present review is to provide a further contribution to explaining the effect of amphetamine, methylphenidate, and depolarization by high $\mathrm{K}^{+}$on dopamine release, as estimated by in vivo microdialysis in animal models of ADHD and to compare the evidence obtained with that from in vitro methods. This comparison can le ad to the recognition of the advantages and the limitations of each method used to study the vesicle trafficking involved in dopamine release and provide insight into the etiology of ADHD and the mechanism of the medication effect of psychostimulants.

\section{ANIMAL MODELS OF ADHD}

In vivo experimentation on ADHD medications can be performed in different animal models of ADHD (Davids et al., 2003). Among them, spontaneously hypertensive rats (SHR) (Yamory et al., 1984) have been widely investigated because relative to their Wistar-Kyoto (WKY) normotensive controls, SHR rats show behavioral abnormalities (hyperactivity and hyper-reactivity to stress) (Knardahl \& Sagvolden, 1979) that resemble those of human ADHD. Moreover, when compared with WKY controls, SHR rats exhibit increased activity when exposed to different contexts (Sagvolden et al., 1992a,b), a heightened response to stress with marked increase of plasma catecholamines (Chiueh, 1981), altered reinforcement mechanisms (Berger \& Sagvolden, 1998), deficient sustained attention (Sagvolden, 2000), and impaired acquisition of operant tasks (Wyss, 1992; Mook et al., 1993; Sagvolden, 2000). Spontaneously hypertensive rats also have a reduced number of $\mathrm{Ca}^{2+} /$ calmodulin-dependent proteinkinase II (CaMKII) elements and a lower expression of the peptide product of the FOS family and ZIF-268 in the shell of the nucleus accumbens (NAc) (Papa et al., 1998). Moreover, in SHR rats, CaMKII levels can be normalized by chronic methylphenidate treatment.

In view of the evaluation of the effects of psychostimulants and norepinephrine reuptake 
blockers on SHR rats, we must point out that SHR rats have a greater rate of norepinephrine uptake, mediated by the norepi-nephrine transporter (NET), in the frontal cortex during early development, and that such changes are accounted for by an increased Vmax of the norepinephrine uptake mechanism (Myers et al., 1981). Moreover, the authors detected a significant decrease in dopamine uptake in the frontal cortex and striatum of the SHR at 6 weeks of age, thus suggesting an important role for dopamine in the development of both hypertension and behavioral hyperactivity exhibited by these animals. An interesting study on the expression pattern of the specific genes involved in dopamine neuron differentiation, survival, and functioning during postnatal development of the ventral midbrain in SHR males has shown that tyrosine hydroxylase (TH) and dopamine transporter (DAT) gene expression are significantly reduced in the SHR midbrain during the first month of postnatal development (Leo et al., 2003).

A promising new animal model of ADHD is represented by WKHA rats (Hendley \& Fan, 1992; Hendley, 2000). The WKHA rats, selected by cross-breeding SHR and WKY, are normotensive but maintain certain behavioral features of SHR, such as hyperactivity in a novel environment and hyper-reactivity to stress; WKHA rats are less aggressive than SHR and habituate more readily to a novel environment. Neurochemical studies have suggested that the WKHA strain shows the lowest rate of norepinephrine uptake in the frontal cortex and the highest uptake rate of dopamine when compared with SHR, WKY, and WKHT (a WKYderived strain of hypertensive rats that are not hyperactive).

Another animal model of ADHD is represented by dopamine transporter knockout mice (DAT-KO) (Giros et al., 1996) that have an elevated synaptic dopamine concentration in the striatum and the nucleus accumbens (NAc) (Carboni et al., 2001) and show hyperactivity and learning impairment
(Gainetdinov et al., 1998, 2001). Recently the Naples high-excitability (NHE) rat line was also proposed as an animal model of ADHD for its increased behavioral activity and impaired attention, which might be due to a hyperfunctioning of the meso-corticolimbic dopamine system (Sadile et al., 1993; Papa et al., 1995; 2002; Gonzales-Lima \& Sadile, 2000). In summary, although several animal strains may be hyperactive and show attention deficit, the SHR strain shows the highest number of behavioral symptoms resembling those observed in ADHD (Sagvolden, 2000).

\section{TRANSMITTERS, TRASPORTERS AND BRAIN AREAS INVOLVED IN ADHD}

Investigations on dopamine transmission in the prefrontal cortex (PFCX) and in subcortical areas, i.e. caudate putamen and NAc, has provided clues on the specific neuronal mechanism that could be responsible for the behavioral features of animal models of ADHD (Linthorst et al., 1991; Sagvolden \& Sergeant, 1998; Robbins et al., 2002; Spencer et al., 2002, Solanto, 2002). The PFCX and the ventral tegmental area (VTA) are reciprocally connected by dopamine afferents and glutamatergic efferents. Ventral tegmental area dopamine neurons are involved in working memory and in executive functions, such as motor planning, inhibitoryresponse control, and sustained attention (Fibiger \& Phillips, 1986; Granon et al., 2000; Robbins, 2002). The caudate putamen and the NAc receive a dense innervation from the substantia nigra and the VTA, respectively, and play a crucial role in motor behavior and motivation (Di Chiara et al., 1992; Almaric \& Koob 1993; Woodward et al., 1999). The NAc, in turn, can be subdivided into two regions, the shell and the core (Deutch \& Cameron, 1992; Zham \& Heimer, 1993). Dopamine transmission in the shell is involved in emotional and motivational processes related to reinforcement 
(Di Chiara, 2002). In particular, dopamine transmission in the NAc might be of particular relevance in ADHD because impulsiveness and premature responding may be related to the grade of efficiency or rewarding/reinforcing mechanism (Sagvolden \& Sergeant, 1998).

Children with ADHD tested in attentional tasks were shown to prefer an immediate reinforcement instead of waiting for a delayed one (Sonuga-Barke et al., 1992). Additionally, in tests addressed to show changes in rates of responding throughout fixed-interval schedules of reinforcement of bar-presses for water, SHR behavior was more sensitive to immediate reinforcement but was proportionately less sensitive to delayed reinforcement when compared with the behavior of WKY rats (Sagvolden et al., 1992a, b). In similar tests, the SHR strain can maintain high rates of responding only if reinforcers are infrequent (Sagvolden et al., 1993). Moreover, psychomotor stimulants acted by strengthening the control by delayed reinforcers, an action consistent with clinical observations that ADHD children are less willing than others to accept 'delayed gratification' and that methyl-phenidate increases the control of delayed reward over their behavior (Sagvolden et al., 1992a, b).

Although DAT-KO mice show hyperactivity and an elevated dopamine synaptic concentration, studies on the function of the DAT in ADHD suggest a higher expression of DAT sites in the basal ganglia of adults that suffered from ADHD during childhood (Dougherty et al., 1999) and in children affected by ADHD (Cheon et al., 2003). Therefore, the role of the DAT in the behavioral features of ADHD subjects or in animal models of ADHD remains to be elucidated. Moreover, a correlation between the expression of DAT and the severity of symptoms was not found in these studies. A higher expression of DAT sites was also found in the caudate-putamen of SHR compared with WKY rats, both at pre- and post-hypertensive stages, (Watanabe et al., 1997). Kujirai et al.
(1990), however, did not find any difference between SHR and WKY in ${ }^{3} \mathrm{H}$-mazindol-labeled dopamine uptake sites.

Understanding the consequences of an alteration of DAT expression in ADHD is further complicated by the brain area considered. If indeed, in areas like the caudate putamen and the NAc, the DAT is the primary mechanism of clearance of dopamine released, then a different situation may be encountered in the PFCX, where the role of DAT and eventually its alteration is less clear because the clearance of transmitters is accomplished mainly by diffusion rather than by reuptake in dopamine terminals. In the PFCX, indeed a lower number of DAT sites are present as compared with the NAc and striatum (Garris \& Wightman 1994; Clements 1996; Sesak et al., 1998).

A contribution to the removal of dopamine from the extracellular space in the PFCX can also be provided by norepinephrine terminals (Carboni et al., 1990, Yamamoto \& Novotney, 1988). The expression of DAT in the NAc of SHR rats is unknown; how a higher expression of DAT might explain the higher basal dopamine concentration in the NAc of SHR rats as compared with WKY rats (Carboni et al., 2003) is unclear. It is indeed more likely that a higher synaptic dopamine concentration is associated with reduced DAT activity. An increased number of DAT sites and the consequent reduced dopamine synaptic concentration hardly fit with the hyperactivity typical of the ADHD syndrome. In fact, in DAT-KO mice, hypermotility and an elevated extracellular dopamine concentration in the caudate putamen and in the NAc (Carboni et al., 2001) is associated with KO (Giros et al., 1996) and knock down (KD) (Zhuang et al., 2001) of the DAT gene.

Moreover, as amphetamine reduces hypermotility in DAT-KO mice, it has been suggested that DAT-KO and DAT-KD support the hyperdopaminergic hypothesis of ADHD (Solanto, 2002; Russell, 2002). This suggestion is supported 
by the finding that the dopamine agonist apomorphine, although producing biphasic effects (hypomotility at low doses and hypermotility at high doses) in wild mice and in WKY rats, induces only hypomotility in KD mice and SHR rats at low and high doses (Fuller et al., 1983; Zhuang et al., 2001).

\section{MECHANISM OF ACTION OF DRUGS USED IN ADHD THERAPY}

Most studies aiming to clarify the mechanism of action of amphetamine have been addressed to vesicle trafficking in the dopamine terminal. Amphetamine can enter the terminal, either through the DAT (Liang \& Rutledge, 1982) or by membrane diffusion, due to its lipophilic properties (Mack \& Bonisch, 1979). In the neuron terminal, amphetamine can label the vesicular monoamine transporter VMAT2 (Sulzer \& Rayport, 1990) and, dissipating the $\mathrm{pH}$ that drives vesicular monoamine uptake (Sulzer et al., 1995), generates the dopamine efflux (Heikkila, 1975). Dopamine, in turn, can diffuse into the terminal cytoplasm and leave it through the inversion of the transport direction of the DAT (Sulzer et al., 1995; Jones et al., 1998). Vesicular monoamine stores, therefore, can play a significant role in locomotor activity, attention, and reinforcing processes as confirmed in heterozygotic VMAT-2 $\mathrm{KO}$ mice, in which amphetamine produces enhanced locomotor activity but diminished behavior reward (Takahashi et al., 1997).

A complementary hypothesis tested in chromaffin cells (Mundorf, 1999) suggests that amphetamine can disrupt vesicular stores to a sufficient degree that $\mathrm{Ca}^{++}$, stored together with dopamine in the terminal vesicles, can escape and trigger the exocytosis of vesicles that are close to the plasmalemmal membrane. A similar mechanism has been proposed for neuronal systems, such as the cholinergic terminals, where acetylcholine release can occur during large inward calcium currents involving many simultaneously opening channels but also through very small calcium transients' entry through only one channel opening at a time (Stanley, 1993).

A more intriguing action of amphetamine was observed in the rat amygdala, where it induces long-term depression of synaptic transmission by $\mathrm{CB}_{1}$ cannabinoid receptors. Amphetamine-induced endocannabinoid release depends indeed on a rise in intracellular calcium by an undisclosed, mechanism (Huang et al., 2003). The possible effect of amphetamine on cannabinoid transmission in ADHD subjects or in animal models can be investigated further in view of the studies by Ehrenreich et al., (1999), who tested the hypothesis that chronic interference by cannabis with endogenous cannabinoid systems during peripubertal development can cause specific and persistent alterations of attentional functions. The authors indeed reported that beginning cannabis use during early adolescence could lead to enduring effects on specific attentional functions in adulthood. Inherent with this evidence, Viggiano et al. (2003) studied the influence of endocannabinoid as a neurotrophic factor on developing mesencephalic dopamine neurons in NHE rats using a prenatal elevation of anandamide. The authors reported that the offspring of rats treated with AM-404 showed a reduction in behavioral activity and attention tests.

Methylphenidate is the drug of choice for ADHD treatment (Swanson \& Volkow, 2002). The drug shows a high affinity for the DAT and NET and much less for the serotonin transporter (SERT) (Gatley et al., 1996). The in vivo potency of methylphenidate on the DAT in the human brain is similar to that of cocaine (Volkow et al., 1999). Additionally, its psychopharmacological properties, evaluated in behavioral, assays are similar to those of cocaine (Gatley et al., 1999). The therapeutic mechanism of action of methylphenidate in ADHD is very complex and is related to chronic treatment 
with oral doses. Methylphenidate, given orally to humans, blocks up to $60 \%$ of DAT sites (Volkow et al., 2002) and increases extracellular dopamine concentrations in the striatum by $16 \pm 8 \%$. If we assume that DAT function is higher in ADHD patients than in unaffected subjects, then this effect could compensate the reduced dopamine function resulting from DAT overexpression. Moreover, the overexpression of DAT sites could be the primary alteration in the dopamine transmission machinery. This alteration, in the absence of an augmented firing, would therefore generate a reduction in the synaptic dopamine concentration, determining a reduced dopamine function. This possibility would be in agreement with the 'dopamine hypofunction hypothesis' (Sagvolden \& Sergeant, 1998). This hypothesis is mainly based on the mechanism of action of methylphenidate, a first drug of choice in ADHD therapy, and is supported by the higher number of DAT sites found in SHR rats as compared with WKY (Watanabe et al., 1997) but not by the geneexpression studies that have shown a lower level of DAT in SHR as compared with WKY rats (Leo et al., 2003).

On the other hand, methylphenidate, at oral doses in the range of those that are used in ADHD, reportedly increases norepinephrine in the hippocampus and in the PFCX, but not in subcortical striatal areas (Kuczenski \& Segal, 2002). This effect might be the result of a methylphenidateinduced blockade of the NET (Gatley et al., 1996). This effect, in turn, might be shared by antidepressants that are currently used clinically (Pliszka, 2003). Tricyclic antidepressants have indeed an efficacy comparable to that of stimulants, although several side effects may hamper their use (Spencer et al., 2002). In particular, the specific NET blocker atomoxetine increases the concentration of norepinephrine and dopamine in the PFCX, without affecting serotonin, whereas it does not change dopamine concentration in the striatum (Bymaster et al.,
2002). Atomoxetine is well tolerated and has been proposed as a valuable new treatment option for adults with ADHD (Simpson \& Plosker, 2004). In agreement with a major role of norepinephrine in the amphetamine therapeutic effect is the observation that amphetamine releases norepinephrine more potently than dopamine and serotonin do, and that the oral dose of these stimulants, which produce amphetamine-type subjective effects in humans, correlates with the their potency in releasing norepinephrine but not dopamine (Rotman et al., 2001).

Elevated dopamine transmission, on the other hand, has been considered a possible cause of the ADHD disorder (Papa et al., 2002; Seeman \& Madras, 2002). According to this hypothesis, methylphenidate, by increasing the dopamine concentration on the D2/D3 autoreceptor, would reduce tonic dopamine release and postsynaptic dopamine function (Grace 1991, 2001).

\section{Synaptosomes and vesicle studies}

Synaptosomes are synpatic terminals in suspension, obtained by a process that includes gently grinding brain tissue in an isotonic solution and various centrifugations (Whittaker et al., 1964). Synaptosomes can be used not only to study uptake and neurotransmitter release but also to prepare neurotransmitter vesicles upon osmotic shock. The evaluation of dopamine release in synaptosomes relies on the estimation of the tracer ${ }^{3} \mathrm{H}$-dopamine released together with endogenous dopamine by an artificial depolarization, usually obtained by altering the concentration of $\mathrm{K}^{+}$and $\mathrm{Na}^{+}$in the medium or by changing the electrical field stimulation (Middlemiss \& Hutson, 1990; Sandoval et al., 2001; Bowyer et al., 1987).

Because ${ }^{3} \mathrm{H}$-dopamine must be previously loaded in the synaptosomal vesicles to be released, the study of dopamine release from synaptosomes relies on the assumption that the dopamine captured is loaded in vesicles that are routinely 
loaded with newly synthesized dopamine in the terminal. This assumption is sustained by the observation of Cerrito et al. (1980), who reported that newly synthesized and recaptured dopamine have similar compartmentation in nerve endings. Alternatively, the endogenous transmitter released from synaptosomes can be assayed by HPLC (Middlemiss \& Hutson, 1990).

The effect of amphetamine on neurotransmitter release in synaptosomes and vesicles has been studied widely. Amphetamine can enter into the synaptosomal preparation through a saturable active transport, as studied by the uptake of ${ }^{3} \mathrm{H}$-amphetamine (Zaczek et al., 1991). Amphetamine can determine the release of previously loaded ${ }^{3} \mathrm{H}$-dopamine from striatal synaptosomes vesicles that share the feature of being the target of reserpine (Masuoka, 1982). As mentioned in the previous paragraph, besides dopamine, amphetamine and related psychostimulants like 3,4-methylenedioxymethamphetamine (MDMA), (+)-methamphetamine, and ephedrine release norepinephrine more potently than they release dopamine and serotonin (Rothman et al., 2001). Furthermore, the authors showed that whereas the psychostimulants rank order of potency for dopamine release was similar to their rank order of potency in published self-administration studies; the oral dose of these stimulants, which produce amphetamine-type subjective effects in humans, correlate with their potency in releasing norepinephrine not dopamine. This observation can influence future research on the mechanism of action of amphetamine in relation to the therapeutic effect on ADHD.

An interesting effect of amphetamine, which might also have implications in ADHD therapy, is its action on dopamine synthesis. The stimulation of dopamine synthesis in rat brain striatal synaptosomes produced by the depolarizing agent veratridine is markedly reduced by prior in vivo amphetamine administration (Patrick et al., 1981). On the other hand, it has been suggested that amphetamine can increase dopamine synthesis, apparently through a mechanism that depends on a functioning uptake carrier as it is prevented by uptake inhibitors like nomifensine and benztropin (Connor \& Kuczenski, 1986).

Amphetamine increases particulate protein kinase $\mathrm{C}$ (PKC) activity in striatal synaptoneurosomes. The increased PKC activity is linked to the outward transport of dopamine and when the release is diminished, the inward transport of amphetamine inhibits PKC instead (Giambalvo, 2003). It would be interesting to test this evidence in synaptoneurosomes from SHR and WKY rats to ascertain any differences that could be related to the different sensitivity of dopamine release due to amphetamine in vivo and in slices (Russell et al., 1998; Carboni et al. 2003).

Among other effects of amphetamine that have been shown in synaptosomal preparations and might have implications in its therapeutic effect is the ability of amphetamine to alter phosphorylationrelated second messenger activities. In particular, amphetamine can enhance the phosphorylation of the neural-specific calmodulin-binding protein, neuromodulin, which, in turn, could contribute to neurochemical events leading to the enhanced release of dopamine and/or a behavioral sensitization (Gnegy et al., 1993). Amphetamine can also increase the phosphorylation of synapsin I in rat striatal synaptosomes, which in turn can play a role in enhanced dopamine release (Iwata et al., 1997). A last interesting observation was obtained in synpatosomes from SHR rats and from WKHA rats, a strain characterized by developing hyperactivity but not hypertension. In SHR rats, a significant increase in norepinephrine uptake, primarily through an increase in Vmax in cerebral cortical areas and the cerebellum, is associated with the hypertensive trait, whereas a significant increase in dopamine uptake Vmax in the frontal cortex is associated with the inheritance of hyperactivity among these strains (Hendley \& Fan, 1992). 


\section{Slice studies}

Another method that has been used to study dopamine release and the effects of drugs used in ADHD therapy is based on the use of slices obtained from a specific brain area. Slices can be a valuable tool for investigating physiological and pharmacological process occurring at the neuron terminal level because drugs can be applied in a relatively quantitative manner, and the effect on the release of a neurotransmitter can be cleaner than the one observed with in vivo methods. (Dunwiddie \& Basile 1983). In slices, dopamine release can be evaluated either by assaying endogenous dopamine or by preloading storage vesicles with ${ }^{3} \mathrm{H}$-dopamine. In the latter case, the amount of radioactivity released into the perfusion chamber, after either an electrically or chemically triggered depolarization, obtained by changing $\mathrm{K}^{+} / \mathrm{Na}^{+}$ concentration in the medium, allows the evaluation of the effect of drugs on depolarization-dependent dopamine release (Dunwiddie \& Basile 1983; Russell 2000; Schmitz et al., 2003).

An interesting study that might have implications for ADHD therapy was performed in striatal slices (Gifford., 2000). Here the author showed that amphetamine-evoked dopamine release at a concentration of 30 micromolar reduced ${ }^{3} \mathrm{H}$ raclopride binding by $77 \%$ with a $50 \%$ inhibition at a a concentration of 1.6 micromolar. Amphetamineevoked dopamine release did not have a significant effect on ${ }^{3} \mathrm{H}-\mathrm{SCH} 23390$ binding, suggesting that dopamine release evoked by low doses of amphetamine would probably act on D2 rather than on D1 receptors. This view could apply to the striatum only because an interesting role of D1 transmission in the PFCX related to attentional performance has been suggested recently (Granon et al., 2000).

Moreover, in a striatal slice preparation, Park and Park (2000) showed that $74 \%$ of ${ }^{3} \mathrm{H}$-raclopride binding was displaced by the dopamine released by amphetamine, and that synaptic dopamine concentration should correspond to $1.6 \mathrm{nM}$. The development of electrochemical recording with small carbon-fibers electrodes has permitted the advancement of the knowledge on catecholamine transmission and its presynaptic regulation (Schmitz et al., 2003).

A study using fast cyclic voltammetry reported that the synaptic dopamine concentration evoked by 1 micromolar amphetamine was about 0.6 and 0.27 micromolar in the caudate putamen and the NAc, respectively (Wieczorek \& Kruk, 1994). The action of amphetamine was also investigated using fast-scan cyclic voltammetry by Jones et al. (1998). The authors confirmed not only that DAT is essential for amphetamine-induced dopamine release but also that amphetamine can pass through the plasma membrane to deplete terminal vesicles, as demonstrated by the disappearance of electrically stimulated dopamine release in striatal slices of DAT-KO mice after the application of 10 micromolar amphetamine. The authors also reported that amphetamine vesicle depletion prevents dopamine electrically stimulated release, probably by affecting all the dopamine containing vesicle in wild type mice. This observation is apparently in contrast to the observation of Anderson et al. (1998), who reported that only large dense-core vesicles (LDCV) are affected by low doses of amphetamine because it has to be considered that the results were obtained in two different models, a mammal on one side and a mollusk (Planorbis corneus) on the other. The evaluation of the synaptic dopamine concentration evoked by amphetamine can therefore provide useful insight into the indirect receptor activity of amphetamine, although the dopamine concentration measured differs from study to study.

The response of slices obtained from brain areas involved in ADHD, such as the caudate putamen, NAc, and PFCX, to methylphenidate and amphetamine has been widely investigated by Russell and coworkers (Russell et al., 1995, 1998; Russell, 2000, 2002). The authors reported that in 
NAc slices of SHR rats, methylphenidate (10 micromolar) released dopamine to a lesser extent than in WKY rats. By contrast, amphetamine stimulated dopamine release to a greater extent in NAc slices from SHR rats than in those from WKY rats. These effects, however, were obtained only at one of the drug concentrations tested. Electrical depolarization, in the presence or in the absence of methylphenidate, on the other hand, stimulated the release of ${ }^{3} \mathrm{H}$-dopamine in the NAc of SHR to a similar extent as in the NAc of WKY rats. On the other hand, the depolarization $(25 \mathrm{mM}$ $\mathrm{K}^{+}$)-induced release of dopamine from NAc slices of SHR rats was significantly lower than in those from WKY rats (Russell, 2000).

The possibility that amphetamine interacts with dopamine release triggered by high potassium was investigated in striatal synaptosomes and slices by Bowyer et al., (1987). The authors reported that amphetamine evokes ${ }^{3} \mathrm{H}$-dopamine release and inhibits the subsequent $\mathrm{K}^{+}$-evoked ${ }^{3} \mathrm{H}$ dopamine release at a flow perfusion that prevents reuptake, whereas at a flow rate that allows the reuptake, the effect of amphetamine is of lesser extent. On the basis of these results, Bowyer et al. suggested that amphetamine can open voltagedependent $\mathrm{Ca}^{++}$channels that are sensitive to cobalt but not to nifedipine, and that amphetamine can desensitize these voltage-dependent $\mathrm{Ca}^{++}$ channels and inhibit their activation by $\mathrm{K}^{+}$ depolarization. This observation parallels the amphetamine effect of preventing the electrical stimulation of dopamine release in striatal slices (Jones et al., 1998).

\section{Whole cell studies}

Some interesting insight into the mechanism of action of amphetamine was recently provided by Khoshbouei et al. (2003). The authors, using the patch clamp technique in the whole-cell configuration combined with amperometry on human embryonic kidney HEK-293 cells stably transfected with the human DAT, observed that the dopamine efflux mediated by DAT is voltage dependent, electrogenic, and dependent on the intracellular $\mathrm{Na}^{+}$ concentration in the recording electrode. On this basis, the authors suggested that the transport of amphetamine after binding to the DAT causes an inward current, which in turn increases the intracellular concentration of $\mathrm{Na}^{+}$, thereby enhancing the DAT-mediated reverse transport of dopamine toward the synaptic space.

Studies on cells have also suggested a different action of amphetamine on terminal vesicles. Indeed, it has been reported that using carbon fiber microelectrodes, currents transients corresponding to individual exocytotic events can be recorded from the cell body of the dopamine-containing neuron of the giant dopamine cell of Planorbis corneus (Anderson et al., 1998). In these preparations, amphetamine at low doses selectively caused the depletion of LDCV, leaving intact the small synaptic vesicles (SSV), although SSV vesicles should be located densely packed in the plasma membrane vicinity. At high doses, amphetamine depletes small vesicles more strongly than large vesicles but continues to deplete large vesicles in a dose dependent manner. On the other hand, in rat NAc catecholamine terminals, identified by immunocytochemical localization of $\mathrm{TH}$, both LDCV and SSV were detected (Bouyer et al., 1984). The authors also reported that a certain proportion of $\mathrm{TH}$-containing terminals within the NAc are morphologically distinct from the catecholaminergic terminals within the dorsal striatum.

If we now assume that in the rat neuron, specifically in NAc terminals, some of the above described mechanisms occur, then it becomes challenging to speculate that the higher amount of dopamine released by amphetamine in SHR rats than in WKY rats (Carboni et al., 2003) could be due to the capability of low doses of amphetamine to deplete a pool of LDCVs that might be located in greater proportion in SHR terminals. On the other 
hand, the larger dopamine release observed in WKY rats resulting from depolarization by high $\mathrm{K}^{+}$might be explained, supposing that high $\mathrm{K}^{+}$acts at least preferentially on the SSV-containing dopamine pool, which is larger in WKY rats than in SHR rats. Therefore, it cannot be excluded that a different distribution of LDCV and SSV in the catecholamine terminals of basal ganglia and eventually in other brain areas, might be a morphological and functional feature that plays a role in the etiology of ADHD.

\section{In vivo studies}

Among the methods used to elucidate the mechanisms involved in the release of a neurotransmitter, microdialysis offers the advantage of evaluating the concentration of a transmitter in the dialysate, which directly reflects the extracellular concentration at the synaptic clefts. The concentration at the synaptic clefts, in turn, depends on the amount released by a firing- and calcium-dependent process and on the efficiency of the reuptake system in removing the transmitter from the synaptic cleft.

Dopamine release from both dendrites and terminals can be assayed in vivo in unanesthetized rats using the microdialysis method (Di Chiara, 1990; Di Chiara et al., 1996; Justice, 1993; Westerink, 2000; Carboni, 2003). The microdialysis technique, therefore, allows the evaluation of endogenous dopamine that, after being released by a depolarization/ calcium-dependent process, escapes from the synaptic cleft, and reaches the microdialysis fiber to be collected in the artificial cerebrospinal fluid. Moreover, the synaptic dopamine concentration is dependent on the capturing capability of the DAT and therefore depends on the firing activity of the terminal and on the density of DAT sites in the area studied. Even in microdialysis, it is possible to study dopamine release triggered by an artificial depolarization, which can be achieved in the area surrounding the microdialysis fiber by perfusing the fiber with an artificial cerebrospinal fluid containing an elevated $\mathrm{K}^{+}$concentration.

The acute and chronic effects of amphetamine and/or methylphenidate have been widely studied by microdialysis (Carboni et al., 1989; Cadoni et al., 1995; Kuczenski et al., 1995; Carboni et al., 2003). Cadoni et al. (1995), investigating the role of vesicular and newly synthesized dopamine in the action of amphetamine, reported that the increase of extracellular dopamine evoked by amphetamine ( 0.2 and $0.5 \mathrm{mg} / \mathrm{kg} \mathrm{s.c.)}$ in the dorsal striatum, was only partially prevented by the blockade of dopamine synthesis by alpha-methylp-tyrosine pretreatment or by the inactivation of vesicular amine uptake by reserpine pretreatment. The combined treatment instead produced a dramatic reduction of the amphetamine-evoked dopamine output.

Kuczenski et al. (1995) reported that both amphetamine and methylphenidate $(2 \mathrm{mg} / \mathrm{kg}$ s.c.) promote the equivalent increase of dopamine output in the caudate, whereas amphetamine is more potent in raising the synaptic concentration of norepinephrine in the hippocampus. We recently reported (Carboni et al., 2003) that the systemic administration of amphetamine (0.25 and 0.5 $\mathrm{mg} / \mathrm{kg} \mathrm{s.c.}$ ) and methylphenidate (1 or $2 \mathrm{mg} / \mathrm{kg}$ i.p.) produces a higher increase in dialysate dopamine in the shell of SHR than in the shell of WKY rats. In contrast, when the microdialysis fiber was perfused with 30 or $60 \mathrm{mM} \mathrm{K}^{+}$through reverse dialysis, the increase of the dialysate dopamine was lower in SHR rats than in WKY rats. The results, compared and critically discussed with the results of other studies investigating the effect of amphetamine, methyl-phenidate, and high potassium depolarization, using in vitro preparations, suggest the existence of different dopamine-containing vesicle pools in the NAc shell dopamine terminals of SHR and WKY rats.

Moreover, we reported that the basal extracellular dopamine concentration in the NAc shell is higher in SHR rats than in WKY rats. On the 
other hand, no difference between SHR and WKY rats, in both basal and amphetamine-induced striatal dopamine release and metabolites, was found by Ferguson et al. (2003). This result is in contrast with what we recently reported (Carboni et al., 2003), but an explanation can be found in the different age of the rats used (6-week-old rats in our study versus 19-week-old rats in the Ferguson study) and in the brain area investigated (NAc in our study, striatum in Ferguson study).

Yu et al. (1990) found no difference between dopamine levels in the striata and NAc from 9week-old WKY and SHR rats. In groups treated acutely with cocaine, the dopamine levels in these two brain regions were surprisingly unaffected, whereas $2 \mathrm{~h}$ after the administration of cocaine, both strains showed a significant increase in striatal HVA. Subacute cocaine administration in WKY and SHR, however, affected dopamine levels in the striata and NAc differently. One more study reported a positive, linear correlation between the extracellular levels of dopamine and cocaine for the 60-min period following acute cocaine administration in both SHR and WKY rats. On the other hand, the slope of the linear regression plots obtained from the data of each 15 min sample was slightly, but significantly, higher in conscious SHR than in conscious WKY (Inada et al., 1992).

In summary, in vivo microdialysis studies have been revealed as a very useful tool for investigating the effect of amphetamine and methylphenidate in either normotensive or hypertensive rats, although the differences in the brain area investigated and in the age of the rats hamper a direct comparison of the results.

\section{DISCUSSION}

Synaptic release and consequently the extracellular concentration of dopamine measured depend on a sequence of events that begins with terminal depolarization and ends with the reuptake or the diffusion the transmitter. The higher extracellular concentration of dopamine observed in the NAc of SHR rats than in the NAc of WKY rats (Carboni et al., 2003) suggests that in SHR rats, synaptic transmission in the NAc occurs by means of a higher dopamine concentration in the synaptic cleft. The elevated synaptic dopamine concentration cannot be recognized as being due to either elevated tonic or elevated phasic activity because phasic activity can be measured on a subseconds to seconds timescale (Venton et al., 2003; Grace, 1991, 1995), whereas the amount of transmitter assayed by the microdialysis technique represents an estimate of the average dopamine concentration present at the synaptic cleft for the collecting time (20 $\mathrm{min}$ ). Therefore, the higher synaptic dopamine concentration observed in the NAc of SHR rats can be attributed to a dysfunction at different levels, such as dopamine synthesis, dopamine storage, dopamine metabolism, dopamine reuptake, autoreceptor function, postsynaptic receptor activity, and transduction mechanisms. Unfortunately, basal release cannot be estimated in synaptosomes and might be hampered in slices because of an interruption in the cell bodyterminal connections; therefore, no comparison with the results obtained in vitro can be made.

Although the differences observed in NAcbasal dopamine release is of limited entity, this dissimilarity could represent a crucial transmission alteration that might be involved in the expression of the typical behavioral observed in SHR rats (Knardahl \& Sagvolden, 1979), and it is possible to speculate that children affected by ADHD might have in common with SHR rats an elevated dopamine transmission in the NAc. This view is supported by the increase in $\mathrm{TH}$ activity found in another animal model of ADHD, the Naples highexcitability (NHE) rat (Viggiano et al., 2000, 2002). If one assumes that the SHR phenotype is a model of ADHD, then the higher dopamine basal concentration found in the NAc of SHR as 
compared with WKY rats (Carboni et al., 2 003) favors a hyperdopaminergic hypothesis of this condition. Moreover, SHR rats showed a more pronounced increase of extracellular dopamine in the same area after challenge with amphetamine and methylphenidate. The clear-cut difference between SHR and WKY rats in the responsiveness of NAc-shell dopamine to methylphenidate is particularly relevant, given that this drug is to date the treatment of choice for ADHD. An increased dopamine synthesis in SHR rats seems also supported by the higher expression of TH mRNA levels (Kumai et al., 1996) and TH gene expression (Reja et al., 2002) in the medulla oblongata of SHR rats. On this basis, it has been speculated that an increased dopamine output in the NAc would be compensating for a reduced transduction mechanism (Papa et al., 1998). Consistent with this proposal might be the reduced number of CaMKII-positive elements identified in the anterior portion of the shell together with a lower expression of $c-F O S$.

The larger increase of dialysate dopamine caused by a low doses of amphetamine in SHR, as compared with WKY rats (Carboni et al., 2003), is difficult to attribute to a specific mechanism, considering the existence of multiple evidence and a hypothesis on the mechanism of action of amphetamine. Although many differences are due to the methodology used, the comparison of our data with those from a few in vitro studies in slices conducted by Russell et al. (1998) allows us to point out some common evidence. The authors indeed showed that in slices obtained from the accumbens of SHR and WKY rats, the effect of amphetamine on dopamine release, at the lower dose tested, was higher in SHR than in WKY rats. Moreover, amphetamine at higher doses produced a bigger increase in dopamine release in PFCX slices from SHR than in those from WKY rats. The data are in agreement with a recent observation in our laboratory. We indeed found that amphetamine releases more dopamine in the
PFCX of SHR rats than in WKY rats (Carboni et al., unpublished observations).

When dopamine release is evoked by high $\mathrm{K}^{+}$ concentrations, SHR and WKY rats respond in a strikingly different manner (Carboni et al., 2003). Therefore, if amphetamine releases more dopamine from the NAc shell of SHR rats than from the shell of WKY rats, then the depolarization obtained by perfusion with high- $\mathrm{K}^{+}$Ringer's solution releases more dopamine in WKY than in SHR rats. The data suggest that (a) two pools of releasable dopamine might be available in accumbal dopamine terminals; (b) the pools are differently affected by amphetamine and high $\mathrm{K}^{+}$, and (c) they represent a different source of releasable dopamine in the rat strains SHR and WKY. Our result is in agreement with that reported by Russell (2000). The authors reported indeed that the $25 \mathrm{mM} \mathrm{K}^{+}$-evoked dopamine release in NAc slices from SHR rats is much lower than that observed in slices from WKY rats. It is interesting to note that such a difference was not observed when depolarization was triggered by electrical stimulation (Russell et al., 1998). A higher effect of high $\mathrm{K}^{+}$in SHR rats was reported recently (Yousfi-Alaoui et al., 2001). The authors showed that $15 \mathrm{mM} \mathrm{K}^{+}$-evoked ${ }^{3} \mathrm{H}$-dopamine overflow is lower in the striatum and PFCX synaptosomes from SHR as compared with WKY rats. This evidence allows us to suggest that ${ }^{3} \mathrm{H}$-dopamine used as a tracer in both synaptosomes and slice preparations is evenly distributed among vesicles, no matter if two pools of vesicles eventually are differently mobilized by high $\mathrm{K}^{+}$or by amphetamine.

We recently reported that methylphenidate enhances the extracellular dopamine concentration in the NAc of SHR more than in WKY rats (Carboni et al., 2003). The data from that study, when compared with the data obtained by Russell et al. (1998), are different regarding the effect of methylphenidate. Indeed Russell et al. reported that the methylphenidate effect on the electrically stimulated release of ${ }^{3} \mathrm{H}$-dopamine was not different 
in slices obtained from the NAc of WKY or SHR rats. At the moment, we do not have an explanation for such diversity, but the different density and location of DAT sites in areas such as the NAc, the caudate, and the PFCX may be relevant. The DAT indeed can be densely packed in the synaptic cleft vicinity but also more sparsely located far from the synaptic cleft (Sesak et al., 1998), and this feature might affect the results obtained by different methods. If indeed the dialysate concentration of dopamine measured through the microdialysis technique depends strongly on the DAT function in the striatum, and in the cortex it has been considered that dopamine can be captured also by the NET (Carboni et al., 1989, 2001), therefore the evaluation of dopamine release and the influence of DAT in slices, and even more in synaptosomes, may be different because dopamine is released in much larger spaces.

Upon studies on slices, Russell et al. (2000) concluded that in SHR rats, the DAT function is not probably different from that in WKY rats. If we assume that this conclusion is correct, our data would suggest that the higher effect of methylphenidate observed in SHR rats as compared with WKY rats is merely due to a higher release of dopamine in the synaptic cleft, which is, in turn, in agreement with the higher dopamine basal concentration found in the NAc of SHR rats as compared with WKY rats. This point of view would therefore strengthen the hypothesis (Russell, 2000) that the difference between SHR and WKY rats regarding the response to amphetamine and to high $\mathrm{K}^{+}$lies at the vesicle level.

A further mechanism in which amphetamine is involved is the so called 'redistribution' of VMAT-2 in dopamine terminals (Sandoval et al., 2001, 2002; Fleckenstein \& Hanson, 2003). A single dose of amphetamine indeed, causes a reversible decrease in the function of dopamine uptake in a purified vesicle-enriched fraction and a consequent rise in the extracellular dopamine concentration, with more chances that reactive species derived from oxygen degradation products are formed in the dopamine terminal. An opposite effect has been reported for methylphenidate that instead, it increases dopamine uptake in the vesicle-enriched fraction whilst increasing the number of VMAT-2 sites in the same fraction and decreasing them in plasmalemma-enriched fractions (Fleckenstein \& Hanson, 2003). It is hard to position VMAT-2 'redistribution' in the mechanism of action of psychostimulants in ADHD therapy because both amphetamine and methylphenidate have been used alternatively with therapeutic benefit, but considering the localization of VMAT2 in VTA neurons (Nirenberg et al., 1996) and the effect of amphetamine in KA1 VMAT2 mutant mice (Patel et al., 2003), it cannot be excluded that the defect present in SHR rats and eventually in ADHD is at the level of different LDCV and SSV density and/or VMAT2 expression in the vesicles.

In conclusion, this study supports the usefulness of investigating dopamine release in SHR and WKY rats using different methods for improving either the knowledge on vesicle trafficking at the dopamine-terminal level or the knowledge of the mechanism of action of amphetamine and methylphenidate, therefore contributing to the understanding of ADHD etiology.

\section{ACKNOWLEDGMENTS}

This study was supported by funds from "Ministero Istruzione Università e Ricerca" PRIN 2001-2002 and from "Centro di Eccellenza sulla Neurobiologia delle Dipendenze" of the University of Cagliari and Regione Autonoma Sardegna.

\section{REFERENCES}

Almaric M, Koob GF. 1993. Functionally selective neurochemical afferents and efferents of the mesocorticolimbic and nigrostriatal dopamine system. Prog Brain Res 99: 209-226. 
Anderson BB, Chen G, Gutman dopamine, Ewing AG. 1998. Dopamine levels of two classes of vesicles are differentially depleted by amphetamine. Brain Res 788: 294-301

Berger DF, Sagvolden T. 1998. Sex differences on operant discrimination behaviour in an animal model of attention-deficit hyperactivity disorder. Behav Brain Res 94:73-82.

Biederman J, Spencer T, Wilens T. 1997 Psychopharmacology. In: WIener JM, ed, Textbook of Child and Adolescent Psychiatry. Washington DC, USA: American Psychiatric Press; 779-813.

Bouyer JJ, Joh TH, Pickel VM. 1984. Ultrastructural localization of tyrosine hydroxylase in rat nucleus accumbens. J Comp Neurol. 227: 92-103.

Bowyer JF, Masserano JM, Weiner N. 1987. Inhibitory effects of amphetamine on potassiumstimulated release of $\left[{ }^{3} \mathrm{H}\right]$ dopamine from striatal slices and synaptosomes. J Pharmacol Exp Ther 240: $177-86$

Bymaster FP, Katner JS, Nelson DL, HemrickLuecke SK, Threlkeld PG, Heiligenstein JH, et al. 2002. Atomoxetine increases extracellular levels of norepinephrine and dopamine in prefrontal cortex of rat: a potential mechanism for efficacy in attention deficit/hyperactivity disorder. Neuropsychopharmacology 27: 699-711

Cadoni C, Pinna A, Russi G, Consolo S, Di Chiara G. 1995. Role of vesicular dopamine in the in vivo stimulation of striatal dopamine transmission by amphetamine: evidence from microdialysis and Fos immunohistochemistry. Neuroscience 65: 1027-1039.

Carboni E, Imperato A, Perezzani L, Di Chiara G. 1989. Amphetamine, cocaine, phencyclidine and nomifensine increase extracellular dopamine concentrations preferentially in the nucleus accumbens of freely moving rats. Neuroscience 28: 653-661.

Carboni E, Tanda GL, Frau R, Di Chiara G. 1990. Blockade of the noradrenaline carrier increases extracellular concentration in the prefrontal cortex: evidence that dopamine is taken up in vivo by noradrenergic terminals. J Neurochem 55: 10671070.

Carboni E, Spielowoy C, Vacca C, Nonsten-Bertrand M, Giros B, Di Chiara G. 2001. Cocaine and amphetamine increase extracellular dopamine in the nucleus accumbens of mice lacking the dopamine transporter. J Neurosci 21: RC141

Carboni E. 2003. Microdialysis coupled with electrochemical detection. A way to investigate brain monoamine role in freely moving animals. Methods Mol Med 79: 415-432.

Carboni E, Silvagni A, Valentini V, and Di Chiara G. 2003. Effect of amphetamine, cocaine and depolarization by high potassium on extracellular dopamine in the nucleus accumbens shell of SHR rats. An in vivo microdialysis study. Neurosci Biobehav Rev 27: 653-659.

Cerrito F, Casazza G, Levi G, Raiteri M. 1980. Evidence for a similar compartmentation of recaptured and endogenously synthesized dopamine in striatal synaptosomes. Neurochem Res 5:115-21.

Cheon KA, Ryu YH, Kim YK, Namkoong K, Kim $\mathrm{CH}$, Lee JD. 2003. Dopamine transporter density in the basal ganglia assessed with [(123)I]IPT SPET in children with attention deficit hyperactivity disorder. Eur J Nucl Med Mol Imaging 30: 306-311.

Chiueh CC, McCarty R. 1981. Sympatho-adrenal hyperreactivity to footshock stress but not to cold exposure in spontaneously hypertensive rats. Physiol Behav 26: 85-89.

Clements JD. 1996. Transmitter timecourse in the synaptic cleft: its role in central synaptic function. Trends Neurosci 19:163-171.

Connor CE, Kuczenski R. 1986. Evidence that amphetamine and $\mathrm{Na}^{+}$gradient reversal increase striatal synaptosomal dopamine synthesis through carrier-mediated efflux of dopamine. Biochem Pharmacol 35: 3123-3130.

Davids E, Zhang K, Tarazi FI, Baldessarini RJ. 2003. Animals models of attention-deficit hyperactivity disorder. Brain Res Rev 42:1-21.

Deutch AY, Cameron DS. 1992. Pharmacological characterization of dopamine systems in the nucleus accumbens core and shell. Neuroscience 46: 49-56.

Di Chiara G. 1990. In vivo brain dialysis of neurotransmitters. Trends Pharmacol Sci 11: 116-121.

Di Chiara G, Acquas E, Carboni E. 1992. Drug motivation and abuse: a neurobiological perspective. Ann N Y Acad Sci 654: 207-219.

Di Chiara G, Tanda G, and Carboni E. 1996. Estimation of in-vivo neurotransmitter release by brain microdialysis: the issue of validity. Behav Pharmacol 7: 640-657.

Di Chiara G. 2002. Nucleus accumbens shell and core dopamine: differential role in behavior and 
addiction. Behav Brain Res 137:75-114.

Dougherty DD, Bonab AA, Spencer TJ, Rauch SL, Madsras BK, Fishman AJ. 1999. Dopamine transporter density in patients with attention deficit hyperactivity disorder. Lancet 354: 2132-2133.

Dunwiddie T, Mueller A, Basile A. 1983. The use of brain slices in central nervous system pharmacology. Fed Proc 42: 2891-2898.

Ehrenreich H, Rinn T, Kunert HJ, Moeller MR, Poser W, Schilling L, et al. 1999. Specific attentional dysfunction in adults following early start of cannabis use. Psychopharmacology (Berl). 142: 295-301.

Faraone SV, Biederman J. Pathophysiology of attention-deficit/hyperactivity disorder. In: Davis KL, Charney D, Coyle JT, Nemeroff C, eds, Neuropsychopharmacology: The Fifth Generation of Progress. Philadelphia, Pennsylvania, USA: Lippincott Williams \& Wilkins; 577-596.

Ferguson SA, Gough BJ, Cada AM. 2003. In vivo basal and amphetamine-induced striatal dopamine and metabolite levels are similar in the spontaneously hypertensive, Wistar-Kyoto and Sprague-Dawley male rats. Physioi Behav 80: 109-114.

Fibiger HC, Phillips AG. 1986. Reward, motivation, cognition: psychobiology of mesentelencephalic dopamine systems. In: Mountcastle VB, Bloom FE, Geiger SR, eds, Handbook of Physiology. Vol 4: Intrinsic regulatory system of the brain. Section 1: The nervous system. Bethesda, Maryland, USA: American Physiological Society; 647-676.

Fleckenstein AE, Hanson GR. 2003. Impact of psychostimulants on vesicular monoamine transporter function. Eur J Pharmacol 479: 283-289.

Fuller RW, Hemrick-Luecke SK, Wong DT, Pearson D, Threlkeld PG, Hynes MD $3^{\text {rd }} .1983$. Altered behavioral response to a D2 agonist, LY141865, in spontaneously hypertensive rats exhibiting biochemical and endocrine responses similar to those in normotensive rats. J Pharmacol Exp Ther 227: 354-359.

Gainetdinov RR, Jones SR, Fumagalli F, Wightman RM, Caron MG. 1998. Re-evaluation of the role of the dopamine transporter in dopamine homeostasis Brain Res Brain Rev 26: 148-153.

Gainetdinov RR, Caron MG. 2001. Genetics of childhood disorders: XXIV. ADHD, part 8: hyperdopaminergic mice as an animal model of
ADHD. J Am Acad Child Adolesc Psychiatry 40: 380-382.

Garris PA, Wightman RM. 1994. Different kinetics govern dopaminergic transmission in the amygdala, prefrontal cortex, and striatum: an in vivo voltammetric study. J Neurosci 14: 442-450.

Gatley SJ, Pan D, Chen R, Chaturvedi G, Ding YS. 1996. Affinities of methylphenidate derivatives for dopamine, norepinephrine and serotonin transporters. Life Sci 58: 231-239.

Gatley SJ, Volkow ND, Gifford AN, Fowler JS, Dewey SL, Ding YS, et al. 1999. Dopaminetransporter occupancy after intravenous doses of cocaine and methylphenidate in mice and humans. Psychopharmacology (Berl) 146: 93-100.

Giambalvo CT. 2003. Differential effects of amphetamine transport vs. dopamine reverse transport on particulate PKC activity in striatal synaptoneurosomes. Synapse 49: 125-133.

Gifford AN, Park MH, Kash TL, Herman LM, Park $\mathrm{EH}$, Gatley SJ, et al. 2000. Effect of amphetamine-induced dopamine release on radiotracer binding to $\mathrm{D} 1$ and $\mathrm{D} 2$ receptors in rat brain striatal slices. Naunyn Schmiedebergs Arch Pharmacol 362: 413-418.

Giros B, Jaber M, Jones SR, Wightman RM, Caron MG. 1996. Hyperlocomotion and indifference to cocaine and amphetamine in mice lacking the dopamine transporter. Nature 379: 606-612.

Gnegy ME, Hong P, Ferrell ST. 1993. Phosphorylation of neuromodulin in rat striatum after acute and repeated, intermittent amphetamine. Brain Res Mol Brain Res 20: 289-298.

Gonzales-Lima F, Sadile A. 2000. Network operations revealed by brain metabolic mapping in a genetic model of hyperactivity and attention deficit: the naples high- and low-excitability rats. Neurosci Biobehav Rev 24: 157-160.

Grace AA. 1991. Phasic versus tonic dopamine release and the modulation of dopamine system responsivity: a hypothesis for the etiology of schizophrenia. Neuroscience 41: 1-24.

Grace AA. 1995. The tonic/phasic model of dopamine system regulation: its relevance for understanding how stimulant abuse can alter basal ganglia function. Drug Alcohol Depend 37: 111-129.

Grace AA. 2001. Psychostimulant actions on dopamine and limbic system function: relevance to the pathophysiology and treatment of ADHD. In: Solanto MV, Arnsten AFT, Xavier Castellanos 
F, eds, Stimulant Drugs and ADHD. Basic and Clinical Neuroscience. New York, NY, USA: Oxford University Press; 134-155.

Granon S, Passetti F, Thomas KL, Dalley JW, Everitt BJ, Robbins TW. 2000. Enhanced and impaired attentional performance after infusion of D1 dopaminergic receptor agents into rat prefrontal cortex. J Neurosci 20: 1208-1215.

Heikkila RE, Orlansky H, Mytilineou C, Cohen G. 1975. Amphetamine: evaluation of $d$ - and l-isomers as releasing agents and uptake inhibitors for ${ }^{3} \mathrm{H}$ dopamine and ${ }^{3} \mathrm{H}$-norepinephrine in slices of rat neostriatum and cerebral cortex. J Pharmacol Exp Ther 194: 47-56.

Hendley ED. 2000. WKHA rats with hyperactivity and hyperreactivity to stress: a review. Neurosci and Biobehav Rev 24: 41-44.

Hendley ED, Fan XM. 1992. Regional differences in brain norepinephrine and dopamine uptake kinetics in inbred rat strains with hypertension and/or hyperactivity. Brain Res 586: 44-52.

Huang YC, Wang SJ, Chiou LC, Gean PW. 2003. Mediation of amphetamine-induced long-term depression of synaptic transmission by CB1 cannabinoid receptors in the rat amygdala. $J$ Neurosci 23: 10311-10320.

Inada T, Polk K, Jin C, Purser C, Hume A, Hoskins $B$, et al. 1992. Cocaine elevates striatal dopamine efflux in spontaneously hypertensive and WistarKyoto rats. Brain Res Bull 28: 227-231.

Iwata S, Hewlett GH, Gnegy ME. 1997. Amphetamine increases the phosphorylation of neuromodulin and synapsin I in rat striatal synaptosomes. Synapse 26: 281-291.

Jones RS, Gainetdinov RR, Wightman RM, Caron MG. 1998. Mechanisms of amphetamine action revealed in mice lacking the dopamine transporter. J Neurosci 18: 1979-1986.

Justice JB Jr. 1993. Quantitative microdialysis of neurotransmitters. J Neurosci Meth 48: 263-276.

Khoshbouei H, Wang H, Lechleiter JD, Javitch A, Galli A. 2003. Amphetamine-induced dopamine efflux. J Biol Chem 278: 12070-12077.

Knardahl S, Sagvolden T. 1979. Open-field behavior of the spontaneously hypertensive rat. Behav Neural Biol 57: 187-200.

Kuczenski R, Segal DS, Cho AK, Melega W. 1995. Hippocampus norepinephrine, caudate dopamine, and serotonin, and behavioral responses to the stereoisomers of amphetamine and methamphet- amine. J Neurosci 15:1308-1317.

Kuczenski R, Segal DS. 2002. Exposure of adolescent rats to oral methylphenidate: preferential effects on extracellular norepinephrine and absence of sensitization and cross-sensitization to methamphetamine. $J$ Neurosci 22: 7264-7271.

Kujirai K, Przedborski S, Kostic V, Jackson-Lewis V, Fahn S, Cadet JL. 1990. Autoradiography of dopamine receptors and dopamine uptake sites in the spontaneously hypertensive rat. Brain Res Bull 25: 703-709.

Kumai T, Tanaka M, Watanabe M, Nakura H, Tateishi T, Kobayashi S. 1996. Elevated tyrosine hydroxylase mRNA levels in medulla oblongata of spontaneously hypertensive rats. Brain Res Mol Brain Res 36: 197-199.

Leo D, Sorrentino E, Volpicelli F, Eyman M, Greco D, Viggiano et al. 2003. Altered midbrain dopaminergic neurotransmission during development in an animal model of ADHD. Neurosci Biobehav Rev 27:661-691.

Liang NY, Rutledge CO. 1982. Comparison of the release of $[3 \mathrm{H}]$ dopamine from isolated corpus striatum by amphetamine, fenfluramine and unlabelled dopamine. Biochem Pharmacol 31: 983-992.

Linthorst AC, De Lang H, De Jong W, Versteeg DH. 1991. Effect of the dopamine D2 receptor agonist quinpirole on the in vivo release of dopamine in the caudate nucleus of hypertensive rats. Eur $\mathbf{J}$ Pharm 201: 125-133.

Mack F, Bonisch H. 1979. Dissociation constants and lipophilicity of catecholamines and related compounds. Naunyn Schmiedebergs Arch Pharmacol 3: 1-9

Masuoka DT, Alcaraz AF, Schott HF. 1982. [3H]Dopamine release by $d$-amphetamine from striatal synaptosomes of reserpinized rats. Biochem Pharmacol 31: 1969-1974.

Middlemiss DN, Hutson PH. 1990. Measurement of the in vitro release of endogenous monoamine neurotransmitters as a means of identification of prejunctional receptors. J Neurosci Meth 34: 23-28.

Mook DM, Jeffry J. Neuringer A. 1993. Spontaneously hypertensive rats (SHR) readily learn to vary but not repeat instrumental responses. Behav Neural Biol 59: 126-135.

Mundorf ML, Hochstetler SE, Wightman RM. 1999. Amine weak bases disrupt vesicular storage and promote exocytosis in chromaffin cells. J 
Neurochem 73: 2397-2405.

Myers MM, Whittemore SR, Hendley ED. 1981. Changes in catecholamine neuronal uptake and receptor binding in the brains of spontaneously hypertensive rats (SHR). Brain Res 220: 325-338.

Nirenberg MJ, Chan J, Liu Y, Edwards RH, 1996. Pickel VM. Ultrastructural localization of the vesicular monoamine transporter-2 in midbrain dopaminergic neurons: potential sites for somatodendritic storage and release of dopamine. J Neurosci 16: 4135-4145.

Oades RD. 1998. Frontal, temporal and lateralized brain function in children with attention-deficit hyperactivity disorder: a psychophysiological and neuropsychological viewpoint on development. Behav Brain Res 94: 83-95.

Papa M, Pellicano A, Cerbone C, Lamberti-DeMello, Menna T, Buono A, et al. 1995. Immediate early genes and brain DNA remodelling in the Naples high- and low-excitability rat lines following exposure to a spatial novelty. Brain Res Bull 37: 111-118.

Papa M, Sergeant JA, Sadile GA. 1998. Reduced transduction mechanism in the anterior accumbal interface of an animal model of Attention Deficit Hyperactivity Disorder. Behav Brain Res 94: 187-195.

Papa M, Diewald L, Carey MP, Esposito FJ, Gironi Carnevale UA, Sadile AG. 2002. A rostro-caudal dissociation in the dorsal and ventral striatum of the juvenile SHR suggests an anterior hypo- and a posterior hyperfunctioning mesocorticolimbic system. Behav Brain Res. 130: 171-179.

Park MH, Park EH. 2000. Synaptic concentration of dopamine in rat striatal slices in relationship to $[3 \mathrm{H}]$ raclopride binding to the dopamine D2 receptor. Arch Pharm Res 23: 360-366.

Patel J, Mooslehner KA, Chan PM, Emson PC, Stamford JA. 2003. Presynaptic control of striatal dopamine neurotransmission in adult vesicular monoamine transporter 2 (VMAT2) mutant mice. J Neurochem. 85: 898-910.

Patrick RL, Berkowitz AL, Regenstein AC. 1981. Effects of in vivo amphetamine administration on dopamine synthesis regulation in rat brain striatal synaptosomes. J Pharmacol Exp Ther 217: 686691.

Pliszka SR. 2003. Non-stimulant treatment of attention-deficit/hyperactivity disorder. CNS Spectr 8: 253-258.
Reja V, Goodchild AK, Phillips JK, Pilowsky PM. 2002. Tyrosine hydroxylase gene expression in ventrolateral medulla oblongata of WKYY and SHR: a quantitative real-time polymerase chain reaction study. Auton Neurosci 98: 79-84.

Robbins TW. 2002. The 5-choice serial reaction time task: behavioural pharmacology and functional neurochemistry. Psychopharmacology 163: 362380.

Rothman RB, Baumann MH, Dersch CM, Romero DV, Rice KC, Carroll FI, et al. 2001. Amphetamine-type central nervous system stimulants release norepinephrine more potently than they release dopamine and serotonin. Synapse 39: 32-41.

Russell V, de Villiers A, Sagvolden T, Lamm M, Taljaard J. 1998. Differences between electrically-, ritalin- and D-amphetamine-stimulated release of $[3 \mathrm{H}]$ dopamine from brain slices suggest impaired vesicular storage of dopamine in an animal model of Attention-Deficit Hyperactivity Disorder. Behav Brain Res 94: 163-171.

Russell VA. 2000. The nucleus accumbens motorlimbic interface of the spontaneously hypertensive rat as studied in vitro by the superfusion slice technique. Neurosci Biobehav Rev 24: 133-136.

Russell VA. 2002. Hyperdopaminergic and hyponoradrenergic activity in prefrontal cortex slices of an animal model for attention-deficit hyperactivity disorder- the spontaneously hypertensive rat. Behav Brain Res 130: 191-196.

Sadile AG, Lamberti C, Siegfried B, Welzl H. 1993. Circadian activity, nociceptive thresholds, nigrostriatal and mesolimbic dopaminergic activity in the Naples High- and Low-Excitability rat lines. Behav Brain Res 55: 17-27.

Sandoval V, Riddle EL, Ugarte YV, Hanson GR, Fleckenstein AE. 2001. Methamphetamine-induced rapid and reversible changes in dopamine transporter function: an in vitro model. J Neurosci 21: 1413-1419.

Sandoval V, Riddle EL, Hanson GR, Fleckenstein AE. 2002. Methylphenidate redistributes vesicular monoamine transporter-2: role of dopamine receptors. J Neurosci 22: 8705-8710.

Sagvolden T, Hendley ED, Knardahl S. 1992a. Behavior of hypertensive and hyperactive rat strains: Hyperactivity is not unitarily determined. Physiol Behav 52: 49-57.

Sagvolden T, Metzger MA, Schiorbeck HK, Rugland 
AL, Spinnangr I, Sagvolden G. 1992b. The spontaneously hypertensive rat (SHR) as an animal model of childhood hyperactivity (ADHD): changed reactivity to reinforcers and to psychomotor stimulants. Behav Neural Biol 58: 103-112.

Sagvolden T, Metzger MA, Sagvolden G. 1993. Frequent reward eliminates differences in activity between hyperkinetic rats and controls. Behav Neural Biol 59: 225-229.

Sagvolden T, Sergeant JA. 1998. Attention deficit/ hyperactivity disorder-from brain dysfunctions to behavior. Behav Brain Res 94: 1-10.

Sagvolden T. 2000. Behavioral validation of the spontaneously hypertensive rat (SHR) as an animal model of attention-deficit /hyperactivity disorder (ADHD). Neurosci Biobehav Rev 24: 31-39.

Schmitz Y, Benoit-Marand M, Gonon F, Sulzer D. 2003. Presynaptic regulation of dopaminergic neurotransmission. J Neurochem 87: 273-89.

Seeman P, Madras B. 2002. Methylphenidate elevates resting dopamine which lowers the impulsetriggered release of dopamine: a hypothesis. Behav Brain Res 130: 79-83.

Sesack SR, Hawrylak VA, Matus C, Guido MA, Levey AI. 1998. Dopamine axon varicosities in the prelimbic division of the rat prefrontal cortex exhibit sparse immunoreactivity for the dopamine transporter. Neuroscience 18: 2697-2708.

Simpson D, Plosker GL. 2004. Atomoxetine: a review of its use in adults with attention deficit hyperactivity disorder. Drugs 64: 205-222.

Solanto MV. 1998. Neuropsychopharmacological mechanism of stimulant drug action in attention deficit/hyperactivity disorder: a review and integration. Behav Brain Res 94: 127-152.

Solanto MV. 2002. Dopamine dysfunction in ADHD: integrating clinical and basic neuroscience research. Behav Brain Res 130: 65-71.

Sonuga-Barke EJ, Taylor E, Sembi S, Smith J. 1992. Hyperactivity and delay aversion-I. The effect of delay on choice. J Child Psychol Psychiatry 33: 387-398.

Spencer TJ, Biederman J, Wilens TE, Faraone SV. 2002. Overview and neurobiology of attentiondeficit/hyperactivity disorder. J Clin Psychiatry 63 Suppl 12: 3-9.

Stanley EF. 1993. Single calcium channels and acetylcholine release at a presynaptic nerve terminal. Neuron 11: 1007-1011.

Sulzer D, Rayport S. 1990. Amphetamine and other psychostimulants reduce $\mathrm{pH}$ gradients in midbrain dopaminergic neurons and chromaffin granules: a mechanism of action. Neuron 5: 797-808.

Sulzer D, Chen TK, Lau YY, Kristensen H, Rayport S, Ewing A. 1995. Amphetamine redistributes dopamine from synaptic vesicles to the cytosol and promotes reverse transport. J Neurosci 15: 4102-4108.

Swanson JM, Volkow ND. 2 002. Pharmacokinetic and pharmacodynamic properties of stimulants: implications for the design of new treatments for ADHD. Behav Brain Res 130: 73-78.

Takahashi N, Miner LL, Sora I, Ujike H, Revay RS, Kostic, et al. 1997. VMAT2 knockout mice: heterozygotes display reduced amphetamineconditioned reward, enhanced amphetamine locomotion, and enhanced MPTP toxicity. Proc Natl Acad Sci USA 94: 9938-9943.

Venton BJ, Zhang H, Garris PA, Phillips PE, Sulzer D, Wightman RM. 2003. Real-time decoding of dopamine concentration changes in the caudateputamen during tonic and phasic firing. J Neurochem 87: 1284-1295.

Viggiano D, Sadile AG. 2000. Hypertrophic A10 dopamine neurones in a rat model of attentiondeficit hyperactivity disorder (ADHD). Neuroreport 11: 3677-3680.

Viggiano D, Grammatikopoulos G, Sadile AG. 2002. A morphometric evidence for a hyperfunctioning mesolimbic system in an animal model of ADHD. Behav Brain Res 130: 181-189.

Viggiano D, Ruocco LA, Pignatelli M, Grammatikopoulos G, Sadile AG. 2003. Prenatal elevation of endocannabinoids corrects the unbalance between dopamine systems and reduces activity in the Naples High Excitability rats. Neurosci Biobehav Rev 27: 129-139.

Volkow ND, Wang GJ, Fowler JS, Fischman M, Foltin R, Abumrad NN, et al. 1999. Methylphenidate and cocaine have a similar in vivo potency to block dopamine transporters in the human brain. Life Sci 65: PL7-PL12.

Volkow ND, Wang GJ, Fowler JS, Logan J, Franceschi D, Maynard L, et al. 2002. Relationship between blockade of dopamine transporters by oral methylphenidate and the increases in extracellular dopamine: therapeutic implications. Synapse 43: 181-187. 
Watanabe Y, Fujita M, Ito Y, Okada T, Kusuoka H, Nishimura T. 1997. Brain dopamine transporter in spontaneously hypertensive rats. J Nucl Med 38: 470-474.

Westerink BH. 2000. Analysis of biogenic amines in microdialysates of the brain. J Chromatogr B Biomed Sci Appl 747: 21-32.

Whalen CK, Henker B, Buhrmester D, Hinshaw SP, Huber A, Laski K. 1989. Does stimulant medication improve the peer status of hyperactive children? J Consult Clin Psychol 57: 545-549.

Whittaker VP, Michaelson IA, Kirkland RJ. 1964. The separation of synaptic vesicles from nerve-ending particles ('synaptosomes'). Biochem J 90: 293-303.

Wieczorek WJ, Kruk ZL. 1994. Differential action of (+)-amphetamine on electrically evoked dopamine overflow in rat brain slices containing corpus striatum and nucleus accumbens. $\mathrm{Br} \mathrm{J}$ Pharmacol 111: 829-836.

Wilens TE, Biederman J, Spencer TJ, Prince J. 1995. Pharmacotherapy of adult attention deficit/hyperactivity disorder: a review. .J Clin Psychopharmacol 15: 270-279.

Woodward DJ, Chang JY, Janak P, Azarov A, Anstrom K. 1999. Mesolimbic neuronal activity across behavioral states. Ann NY Acad Sci 877: 91-112.

Wyss JM, Fisk G, van Groen T. 1992. Impaired learning and memory in mature spontaneously hypertensive rats. Brain Res 592: 135-140.

Yamamoto BK, Novotney S. 1998. Regulation of extracellular dopamine by the norepinephrine transporter. J Neurochem 71: 274-280.

Yamory Y. 1984. Development of the spontaneously hypertensive rat (SHR) and of various spontaneous rat models and implications. In: De Jong W, ed, Handbook of Hypertension. New York, NY, USA: Elsevier; 224-239.

Yousfi-Alaoui MA, Hospital S, Garcia-Sanz A, Badia A, Clos MV. 2001. Presynaptic modulation of $\mathrm{K}^{+}$evoked $[3 \mathrm{H}]$ dopamine release in striatal and frontal cortical synaptosomes of normotensive and spontaneous-hypertensive rats. Neurochem Res 26: 1271-1275.

Yu ZJ, Lim DK, Hoskins B, Rockhold RW, Ho IK. 1990. Effects of acute and subacute cocaine administration on the CNS dopaminergic system in Wistar-Kyoto and spontaneously hypertensive rats: I. Levels of dopamine and metabolites. Neurochem Res 15: 613-619.

Zaczek R, Culp S, De Souza EB. 1991. Interactions of $[3 \mathrm{H}]$ amphetamine with rat brain synaptosomes. II. Active transport. J Pharmacol Exp Ther 257: 830-835.

Zham DS, Heimer L. 1993. Specificity in the efferent projection of the nucleus accumbens in the rat: comparison of the rostral pole projection patterns with those of the core and shell. J Comp Neurol 327: 220-232.

Zhuang X, Oosting RS, Jones SR, Gainetdinov RR, Miller GW, Caron MG, et al. 2001. Hyperactivity and impaired response habituation in hyperdopaminergic mice. Proc Natl Acad Sci USA 98: 1982-1987. 

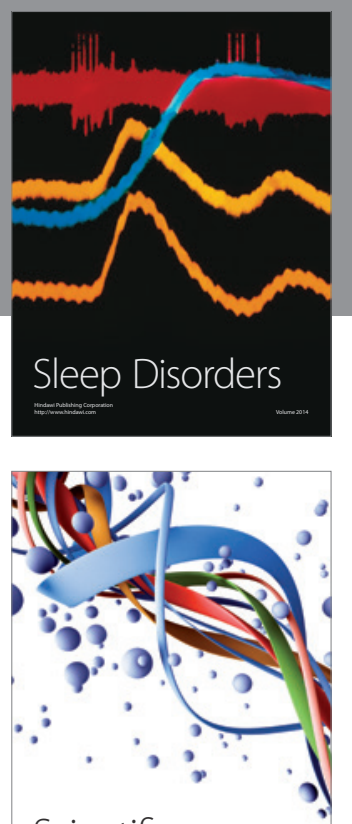

Scientifica
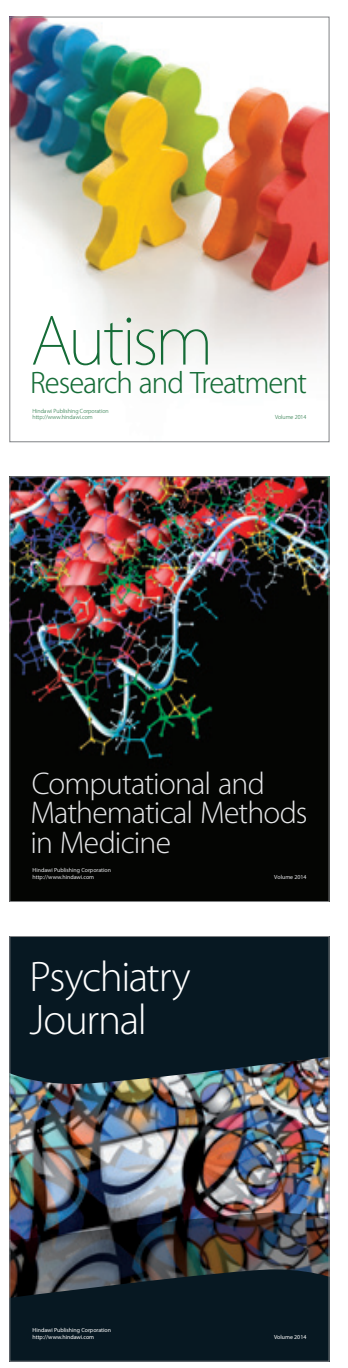
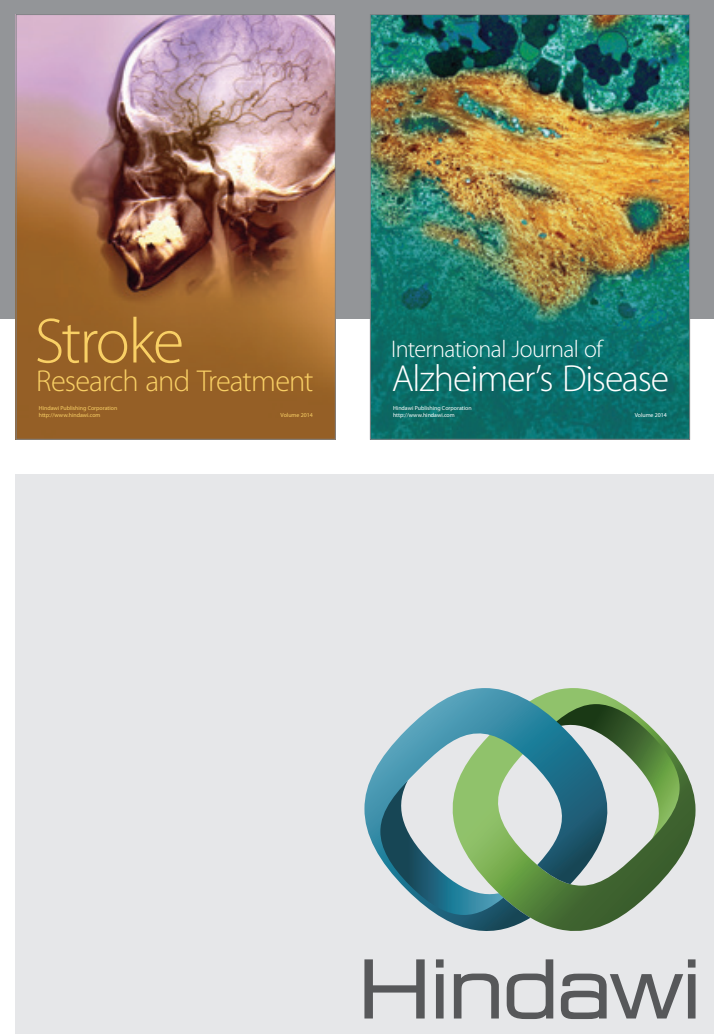

Submit your manuscripts at

http://www.hindawi.com
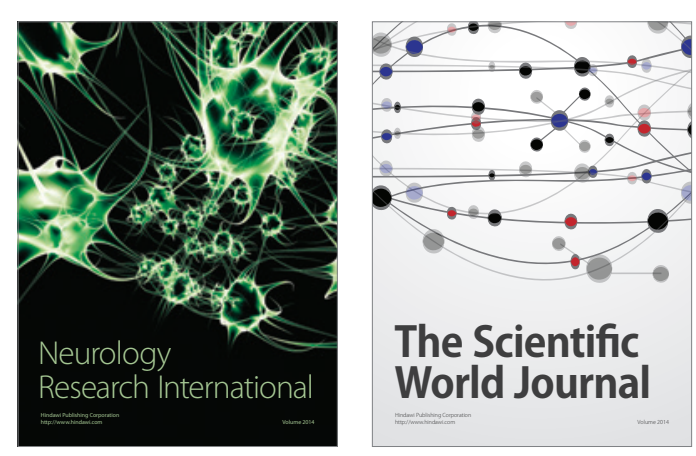

The Scientific World Journal

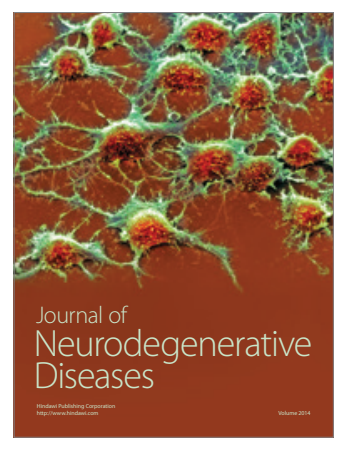

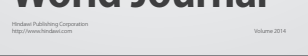

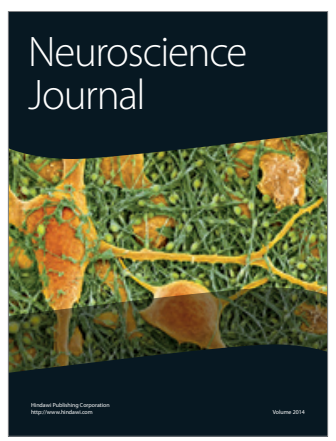

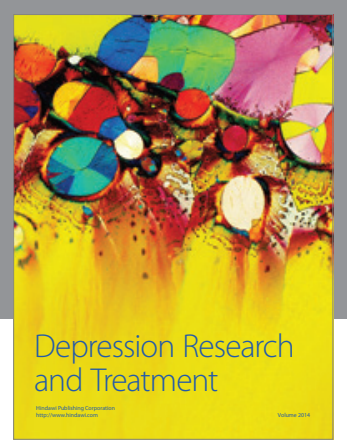
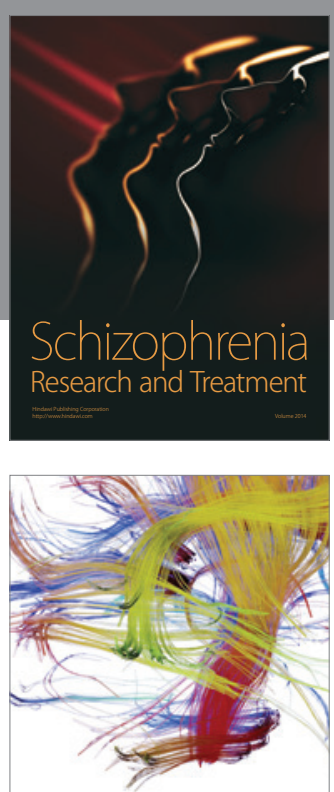

Brain Science

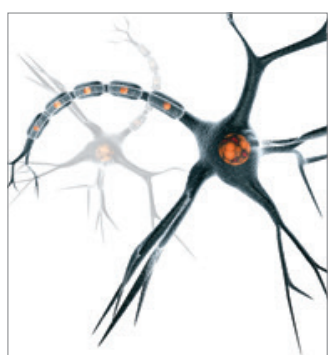

Neural Plasticity
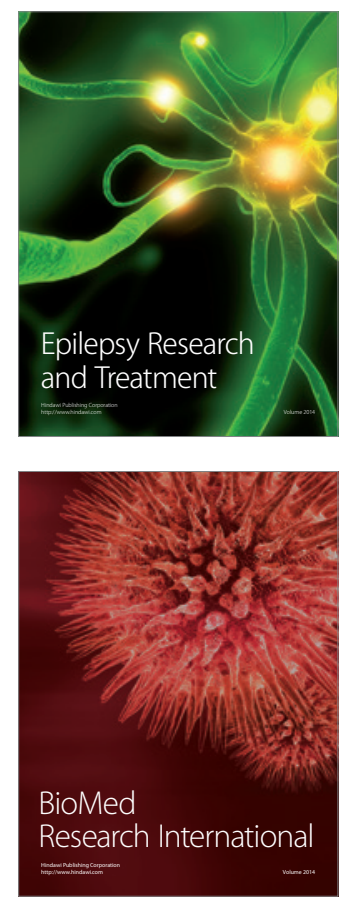

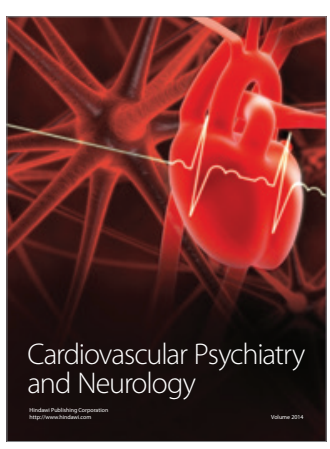

Parkinson's

Disease
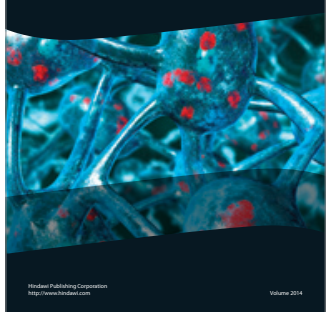